\title{
Determination of Surface Qualities on Inclined Surface Machining with Acoustic Sound Pressure
}

\author{
Arif Gok ${ }^{1}$ - Cevdet Gologlu2,* - Ibrahim H. Demirci² - Mustafa Kurt ${ }^{3}$ \\ ${ }^{1}$ Kastamonu University, Vocational High School, Turkey \\ 2 Karabuk University, Faculty of Engineering, Turkey \\ ${ }^{3}$ Marmara University, Technical Education Faculty, Turkey
}

Die parts used in automotive and aviation industry have complicated surfaces that require multiaxis machining. In machining of inclined surfaces with ball-end milling, the process is of great significance for its correctness and accuracy. In this study, Acoustic Sound Pressure (ASP) generated during the machining of a workpiece at a vertical machining centre has been measured. The experiments have been conducted in association with cutting velocity, feed rate and step over parameters determined by using different surface forms and different cutter path strategies. Therefore, the aim of this study is to understand the relationships between the generated sound signals and surface roughness in the machining of inclined concave and convex surfaces.

In the experiments, the workpiece material of EN X40CrMoV5-1 hot work tool steel, which is commonly used in the related die industry, has been chosen. The ball end mills with two indexable inserts with three different coatings of TiC, TiN, and TiAIN have been used. The results show that there is a rise at the value of surface roughness with a rise at the value of acoustic sound pressure and that surface roughness could be figured out with acoustic sound pressure level.

Key words: ball end milling, acoustic emission and sound pressure, linear regression, surface roughness

\section{O INTRODUCTION}

Machining is one of the most important methods in manufacturing [1]. To change the shape of a workpiece to a desired geometrical shape, it is necessary to use an appropriate machine tool and cutting tools to obtain the required dimensions and surface quality [2]. One of the most important factors to increase the quality in the manufacturing processes is to control surface quality of the product. Surface quality control is a costly process and a difficult task for the parts that are in the production line. Time devoted to quality control process and cost can be minimized by the help of prediction models and systems. Therefore, real-time model-based quality control is used by monitoring measurable processes [3]. The reason behind the monitoring of machining operations is to generally prevent undesired machining consequences such as chip formation and chip shape classification, tool wear, dimensional tolerances, surface texture (roughness and waviness), and tool deflection [4]. Researchers have been working on online monitoring with video based approaches, so that they can screen tool working conditions [5]. However, they are both difficult and costly, so that the implementation of these systems into industry is almost impossible. Nevertheless, when the costs of these systems are reduced, it is likely to use them in many measurements such as tool wear, cutting force, Acoustic Emission (AE) and vibrations [6]. Ghosh et al. [7] focused on the prediction of tool wear in $\mathrm{CNC}$ milling using sensors in integration with neural networks. In their study, they found that the average flank wear of the main cutting edge was predicted by the signals such as cutting force, cutting tool vibration, and sound pressure level obtained from the machining region. Marinescu and Axinte [8] worked on the analysis of emission signals efficiency to determine damages on tool and workpiece in milling operations. At the end of the study, the damage on the tool has been determined with emission signals. Marinescu and Axinte [9] also focused on monitoring of time-acoustic emission frequency to describe surface defects on a workpiece in milling with more than one cutting edge. This was carried out with new methods for supervising cutting processes with multiple teeth cutting simultaneously, i.e. milling, by using of AE signals backed-up by force data. By means of this work, the researchers took signals into consideration for all simultaneous cutting edges. The results showed for the first time that identification of milling conditions (i.e. cutting with one tooth and two-three teeth) is possible using only AE signal in time-frequency domain. Additionally, surface deformations, related to the wearing of cutting edges, can be determined. Rivero et al. [10] worked on evaluation of the suitability of a tool wear monitoring system based on machine tool internal signals. The sensor data from internal signals were compared and analyzed, assessing the deviation in representative variables in time and frequency domains. As a result, tool wear has been estimated. Parallel to these studies, Wilcox et al. [11] worked on the use of cutting force and $\mathrm{AE}$ signals for the monitoring of tool insert geometry during rough face milling. In their studies, they simulated different forms of naturally occurring wear such as crater, notch and flank wear, local changes 
in rake angle and edge breakdown. Weingaertner et al. [12] evaluated the influence of high speed end milling dynamic stability through audio signal measurements both experimentally and analytically. In the study, the stability evaluation was based on the workpiece surface finish and on the audio signals measured with a unidirectional microphone. The experimental and analytical results have been found very close to one another. Tekiner and Yeşilyurt [13] studied the cutting parameters depending on process sound during the turning machining process of AISI 304 austenitic stainless steel. In their study, the best cutting speed and feed rate values were determined according to the flank wear, built up edge, chip form, surface roughness of the machined samples and machine tool power consumption. In addition to the above mentioned studies, Salgado and Alonso [14] focused on Tool Condition Monitoring System (TCMS) for on-line tool wear monitoring in turning. In the study, the monitoring signals were feed motor current and sound signal. The tool wear has been found by TCMS. Ravindra et al. [15] worked on acoustic emissions for tool condition monitoring in metal cutting. Moreover, Haber et al. [16] studied tool-wear monitoring in a high-speed machining process on the basis of the analysis of different signals' signatures in time and frequency domains. In their study, time and frequency domain analyses were confirmed wwith the relevance of cutting-force and vibration signals' signatures for tool-wear monitoring in High-Speed Machining processes. Tool wear has been assessed as a result of their analysis. Quadro and Branco [17] carried out analysis of acoustic emission during drilling test. They used AISI D3, drills of high speed steel with TiN coating. In their measurements, profilometry and light microscopy were used to characterize and quantify the wear on the drills' cutting edges along the tests. In another study, Guo and Ammula [18] developed a real-time acoustic emission monitoring system to investigate the sensitivity of broad AE signal parameters including RMS, frequency, amplitude, and count rate to white layer and corresponding surface finish and tool wear. In this way, tool wear has been observed as real time. Furthermore, Asilturk et al. [19] conducted a study on modeling with regression of surface roughness dependent on cutting parameters, vibration and acoustic emission. In their model, the first degree, the second degree and logarithmic multiple regressions were used. In this way, it was found that the feed rate on the surface roughness parameter was the most effective and the better results were also attained at the second order regression model. Horvat et al. [20] studied on evaluation and monitoring gas metal arc welding process by using an audible sound signal. In this way, the welding process has been assessed in terms of robustness and quality. In addition to this, a new algorithm based on the measured welding current has been established for the calculation of emitted sound during the welding process. The results of experimental and theoretical measurements were found to be in good agreement. Kek and Grum [21] analysed acoustic emission (AE) signals obtained during laser cutting of a steel plate. The acoustic emission signals in the plate have been measured with contact PZT sensors. During the laser cutting process, continuous AE signals have been captured by the action of a cutting gas. AE signals as a result of their research have demonstrated that an important indicator for quality of laser cut. The number of studies related to 3D machining [22] and tool life [23] were also studied by the researchers.

The previous studies focused on acoustic emission, tool wear and deformation, vibrations stability and best cutting parameters. In this study, the experiments were carried out in order to understand the relationships between the sound signals generated and surface roughness in the machining of inclined concave and convex surfaces.

\section{EXPERIMENTAL STUDY}

\subsection{Cutter Path Styles}

It has been experimentally shown that the right choice on tool paths including different cutting movements affects production time, status of machining surfaces and cost [24]. Therefore, in these experimental studies, contouring and ramping tool paths styles are used to produce inclined surfaces. The tool at the machining of free form and inclined surfaces makes movements of ramping and contouring. Accordingly, for the implementation of up milling and down milling strategies at the machining of inclined surface, contouring and ramping are the inevitable choice of tool path styles. In contour operation, the tool moves parallel to the axis parts. As a consequence, the chip is easily disposed from the cutting zone. At the ramping operations, the effective diameter in ball end mill tools is easily visible and their effects to changes in the responses are easily observed. In the experiments, $40 \times 30 \mathrm{~mm}$ islands on the $220 \times 135 \times 50 \mathrm{~mm}$ sized block were machined.

In contouring tool path styles, the cutter scans the inclined surface with the lines in parallel to surface radius (Fig. 1a). On the other hand, in ramping tool path styles, the cutter scans the inclined surface with 
the lines in vertical to surface radius (Fig. 1b). In Fig. 1 , the feed rate and spindle speed are depicted by $V f$ and $W$, respectively.
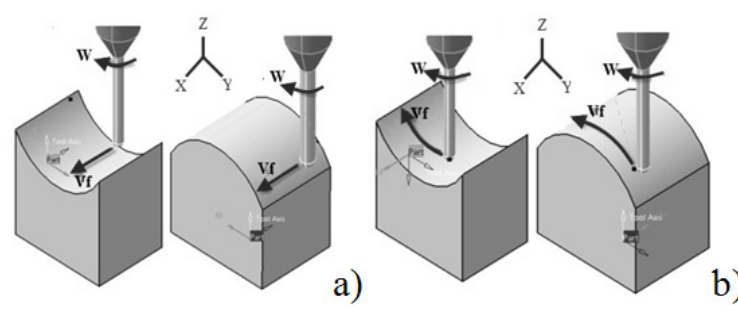

Fig. 1. a) Contouring and, b) ramping cutter path styles for inclined concave and convex surfaces

In both tool path styles, step over values are constant. After machining each step, the cutter moves one step sideways in a position in which it returns back to the beginning level of that step and then processes the next step. Under these conditions, four tool path styles were generated as shown in Fig. 2. In Fig. 2, the form radius of workpiece, milling position angle, nominal depth of cut and step over are shown by $R, \theta, a$ and $f_{p}$, respectively.

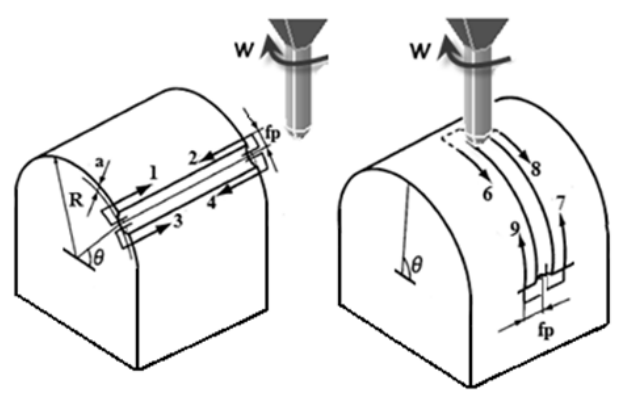

Fig. 2. Cutter path styles- contouring: up milling (up step over) 1 , down milling (up step over) 2, up milling (down step over) 3, down milling (down step over) 4; ramping: up milling (left step over) 5, down milling (left step over) 6, up milling (right step over) 7 , down milling (right step over) 8

\subsection{Material, Cutting Tool and Machining Parameters}

High machinability of the materials used in dies, automotive and space industry is of great importance for surface roughness of the workpiece production. EN X40CrMoV5-1 (Böhler W302) hot work tool steel, which is commonly used in these industries, was preferred in the study. Chemical compositions of the material presented in Table 1. The material has 22 to $25 \mathrm{HRC}$ hardness with yield strength of $1650 \mathrm{~N} /$ $\mathrm{mm}^{2}$. When it is subjected to heat process under 1020 to $1080{ }^{\circ} \mathrm{C}$ for 15 to 30 minutes and cooled in oil, its hardness rises up to 50 to $54 \mathrm{HRC}$. The pre-hardening process is not implemented in its machining process.
After the machining operations are completed, the material is subjected to the heat process. As a cutter body, CoroMill (Sandvik Company) with an indexable (R216-16A20-045), Ø16 mm cylindrical shank, two fluted and $30^{\circ}$ helix angle end mill were used. Moreover, the ball end inserts (Sandvik Company) with TiC, TiN and TiAlN coated (R216-16 03 M-M H13A) were used. Every insert has a coating of 3 micron thickness. In addition to tool path styles, three different variable parameters were used. These were; cutting velocity $(V c)$, feed rate $(V f)$ and cutting step over $(f p)$. Cutting tool step over affects the tracks on the surface made by the cutter, the load on the cutter and the processing time in a direct manner [24]. Step over value was chosen as $5 \%$ of the tool diameter and this value was set as the lower level of $f p$. Cutting velocity and feed rate values were picked up with reference to the catalogue values of Sandvik Company. These reference values were determined by carrying out a number of experiments for each tool coating and by taking the common use of the material for the industry into account (Table 2).

\subsection{Experimental Apparatus and the Implementation of Experiment}

Semi finishing operations were used in the experiments and coolant was not used due to constituting a layer between cutting edge and workpiece, and this layer causes shear in little slices on inclined forms. The experiments were carried out at a vertical machining center, John Ford VMC 550 $\mathrm{CNC}$, having $12000 \mathrm{rev} / \mathrm{min}$ with a $12 \mathrm{~kW}$ engine power. The stages of the experimental system are depicted in Fig. 3. In pre-machining, tool wear did not occur in the machining of several blocks. Thus, every five blocks were machined by different cutting inserts. After completing the pre-machining, a semi finishing operation was carried out using different cutter path styles and parameters on the workpiece. For the combinations of cutting parameters, L'16 standard orthogonal array was chosen as four different levels for each parameter appointed. For concave surface, a number of 48 experiments were conducted with $\mathrm{TiC}$, TiN, and TiAlN coatings (16 experiments per each). Similarly, a number of 48 experiments were made with TiC, TiN, and TiAlN coatings (16 experiments per each) for the convex surface.

Table 1. Chemical composition [wt\%] of EN X40CrMoV5-1

\begin{tabular}{ccccccccc}
\hline & $\mathrm{C}$ & $\mathrm{Si}$ & $\mathrm{Mn}$ & $\mathrm{Cr}$ & $\mathrm{Mo}$ & $\mathrm{P}$ & $\mathrm{V}$ & $\mathrm{S}$ \\
\hline$\%$ & 0.39 & 1.00 & 0.40 & 5.10 & 1.30 & 0.025 & 1.00 & 0.005 \\
\hline
\end{tabular}




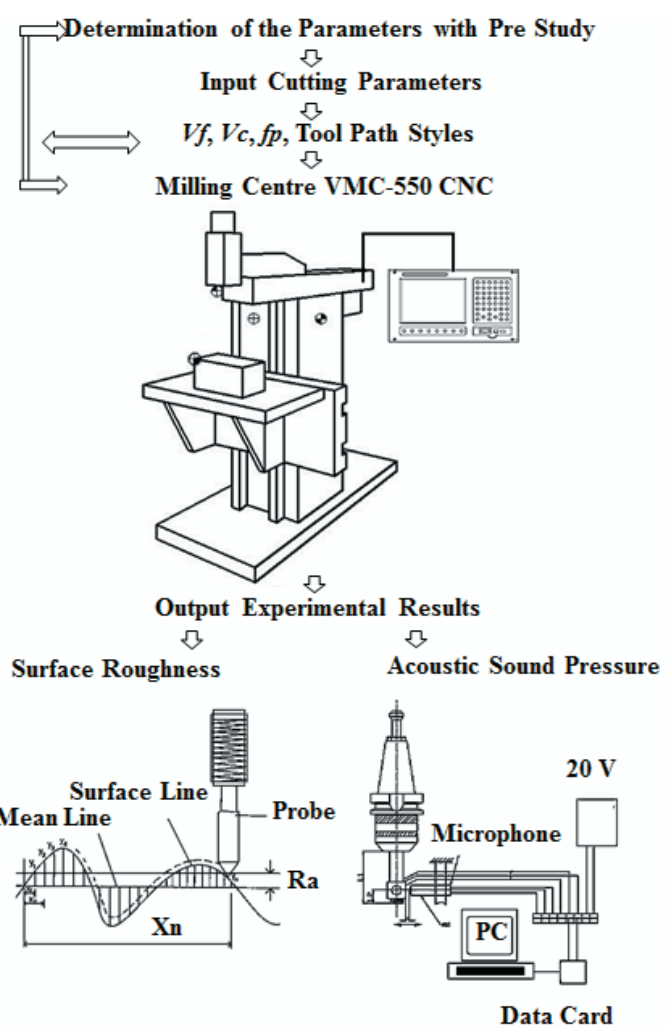

Fig. 3. The stages of the experimental system

Table 2. Assignment of the levels to factors

\begin{tabular}{llcccc}
\hline Factors & & Level 1 & Level 2 & Level 3 & Level 4 \\
\hline \multirow{2}{*}{ Cutting velocity, } & TiC & 70 & 80 & 90 & 100 \\
Vc $[\mathrm{m} / \mathrm{min}]$ & TiN & 100 & 110 & 120 & 130 \\
& TiAIN & 110 & 120 & 130 & 140 \\
\hline \multirow{2}{*}{ Feed rate, } & TiC & 223 & 255 & 286 & 318 \\
Vf $[\mathrm{mm} / \mathrm{rev}]$ & TiN & 318 & 350 & 382 & 414 \\
& TiAIN & 350 & 382 & 414 & 445 \\
\hline Step over, $f p[\mathrm{~mm}]$ & & 0.8 & 1 & 1.5 & 2 \\
\hline
\end{tabular}

\subsection{Measurement of Machining Sound Pressure Level}

Tool defects can be observed by analyzing the sounds generated in machining. In the study, the sound sensor was placed to the closest position to the cutting tool. The acoustic sound pressures were collected by a sound sensor (microphone) at the sampling of 100 $\mathrm{ms}$ in $\mathrm{mV}$ units. An algorithm written in MATLAB is used for digitizing and collecting the sound pressures from the sound sensor. For calibration of the sound sensor, the same sound values were measured at the same time with a sound measurement device of CEMDT 8850. The real sound pressure values were determined by evaluating the differences found via the algorithm. The signals that were recorded in $\mathrm{mV}$ were analyzed in a time scale and its arihe metic mean was calculated. Then, signals were transformed into ASP values in $\mathrm{dB}$. The transformations were made with the Eq. (1).

$$
A S P=20 \log _{10}\left(V_{\text {output }} / V_{o}\right),
$$

where, $V_{\text {output }}$ is the arithmetic mean of the collected signals in Volt and $V_{o}$ is the lowest recorded signals in Volt at the same experiment.

Some significant acoustic sound pressures for the related experiments are given below. In Fig. 4, experiment 3 has the lowest raw sound signal value of $-0.5903 \mathrm{mV}$. On the other hand, the experiment 9 has $-1 \mathrm{mV}$ as the lowest raw sound signal value. The arithmetic mean of the collected signals for the related experiments is given in Table 3 .

Table 3. Acoustic sound pressure values $[\mathrm{mV}]$ of sample experiments

\begin{tabular}{lcc}
\hline & Experiment \#3 & Experiment \#9 \\
\hline Min & -0.5903 & -1 \\
\hline Max & 0.5293 & 0.9725 \\
\hline Arithmetic mean & $1.477 \times 10^{-5}$ & $6.542 \times 10^{-6}$ \\
\hline
\end{tabular}
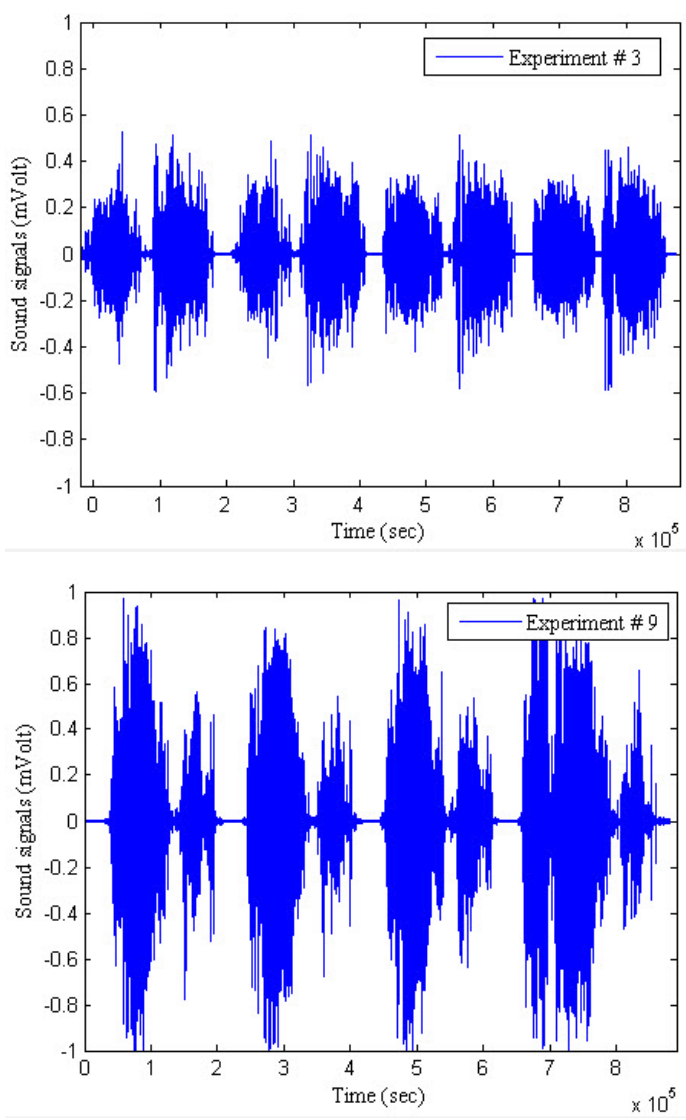

Fig. 4. Samples of the measured acoustic sound 
In the experiments, MahrSurf PS1 surface roughness measurement device was used. The measurements were performed at a direction normal to cutting tool paths with an angle of $45^{\circ}$ to standing position in order to take the effective cutting diameter into consideration in every sample. Average surface roughness $\left(R_{a}\right)$ is represented as in Eq. (2).

$$
R_{a}=\frac{1}{L} \int_{0}^{L}|Y(x)| d x
$$

where, $R_{a}$ represents deviation from the average line, $Y$ represents the ordinate of profile curve and $L$ represents the measurement length. In the experimental measurements, every measurement was carried out three times and their average values have been taken into account.

\section{EXPERIMENTAL RESULTS}

One of the most important criteria for determining surface quality in cutting is surface roughness. The acoustic emission can be employed for predicting surface roughness of machining surfaces [25]. In other words, the relation between surface roughness values and variation of $A S P$ levels can be established. The changes in sound pressure levels have been seen available to determine an average surface roughness.

For concave surface forms, the $A S P[\mathrm{~dB}]$ and surface roughness $[\mu \mathrm{m}]$ values which are acquired from the experiments for the related coatings are shown in Fig. 5. When the acquired $A S P$ and $R_{a}$ graphics for $\mathrm{TiC}, \mathrm{TiN}$ and TiAIN coatings were examined, it wasobserved that surface roughness values increase with the increase in acoustic sound pressure values. However, surface roughness values decrease with the decrease of acoustic sound pressure values.

According to Fig. 5, for the cutter with TiC coating, the largest $A S P$ of $105.2 \mathrm{~dB}$ causes the largest $R_{a}$ value of $5.09 \mu \mathrm{m}$ at the experiment 4 . On the other hand, the lowest $A S P$ of $83.1 \mathrm{~dB}$ is observed at the $R_{a}$ value of $1.51 \mu \mathrm{m}$ at the experiment 1 . For the cutter with TiN coating, the largest $A S P$ of $104.3 \mathrm{~dB}$ resulted in the largest $R_{a}$ value of $5.69 \mu \mathrm{m}$ at the experiment 13. The lowest $A S P$ of $86.1 \mathrm{~dB}$ is observed at the $R_{a}$ value of $1.50 \mu \mathrm{m}$ at the experiment 1 . Lastly, for the cutter with TiAlN coating, the largest $A S P$ of 101.3 $\mathrm{dB}$ resulted in the largest $R_{a}$ value of $5.66 \mu \mathrm{m}$ at the experiment 4. On the other hand, the lowest $A S P$ of $74.1 \mathrm{~dB}$ is observed at the $R_{a}$ value of $1.68 \mu \mathrm{m}$ at the experiment 1 . When the results are evaluated in terms of parameters ( $V f$ and $f p$ ), $A S P$ and $R_{a}$ values show an increase with the increase of feed rate and step over. The effects of feed rate and step over values on obtained $A S P$ and $R_{a}$ values are given in Fig. 6 .

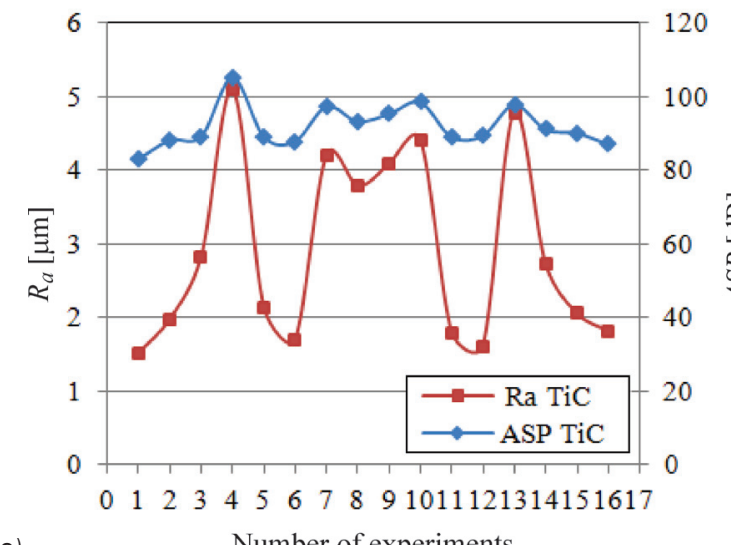

a)

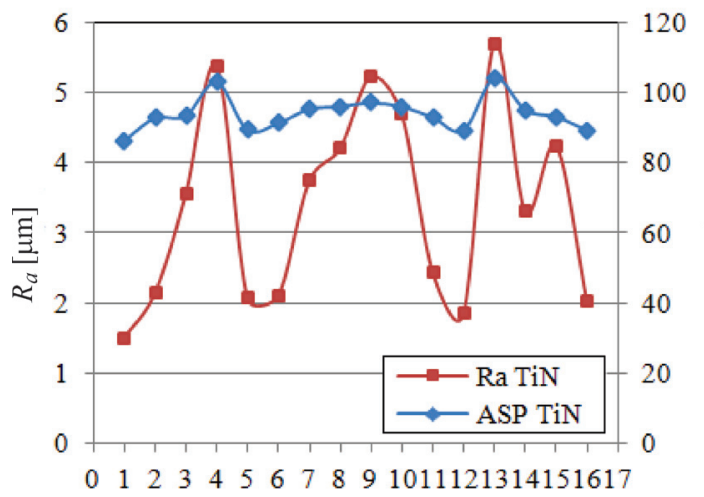

b)

Number of experiments

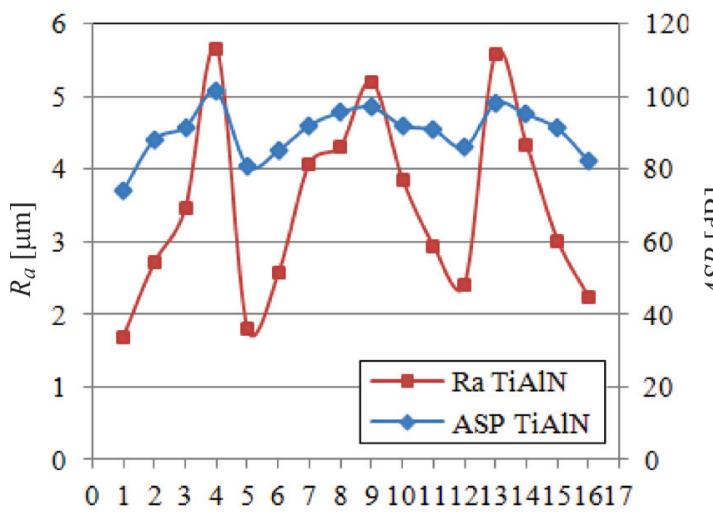

c) Number of experiments

Fig. 5. $R_{a}$ versus ASP for; a) TiC, b)TiN, and c) TiAIN coatings in concave surface

According to Fig. 6a, for the TiC coating, the largest values of $R_{a}$ and $A S P$ have been observed at the feed rate of $318 \mathrm{~mm} / \mathrm{rev}$ and the step over of $2 \mathrm{~mm}$. The lowest values of $R_{a}$ and $A S P$ have been observed at the feed rate of $223 \mathrm{~mm} / \mathrm{rev}$ and the step over of 


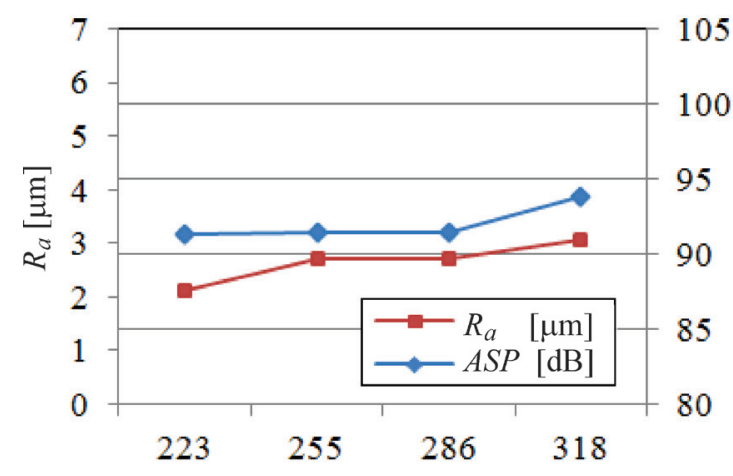

a)

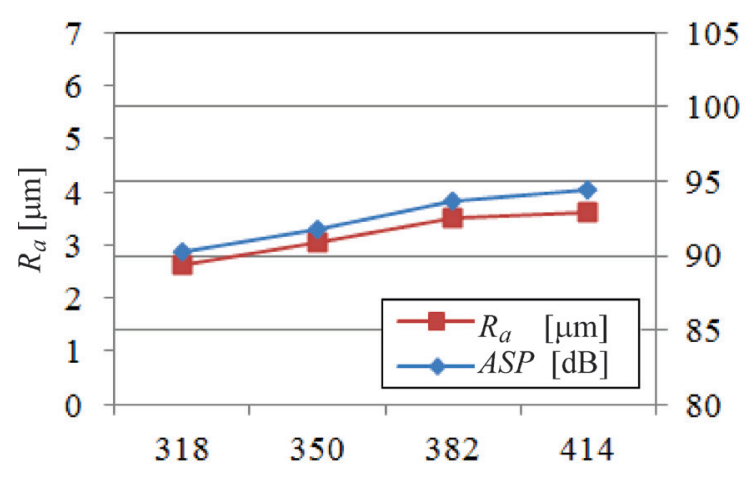

b)

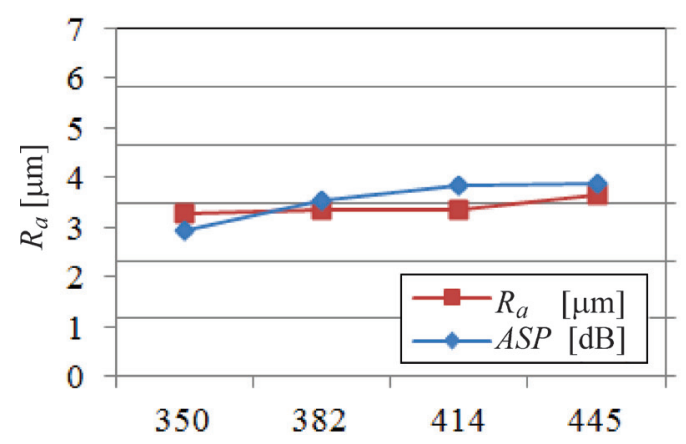

c)

Feed rate $[\mathrm{mm} / \mathrm{rev}]$

105

100

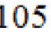

100

85

80

75
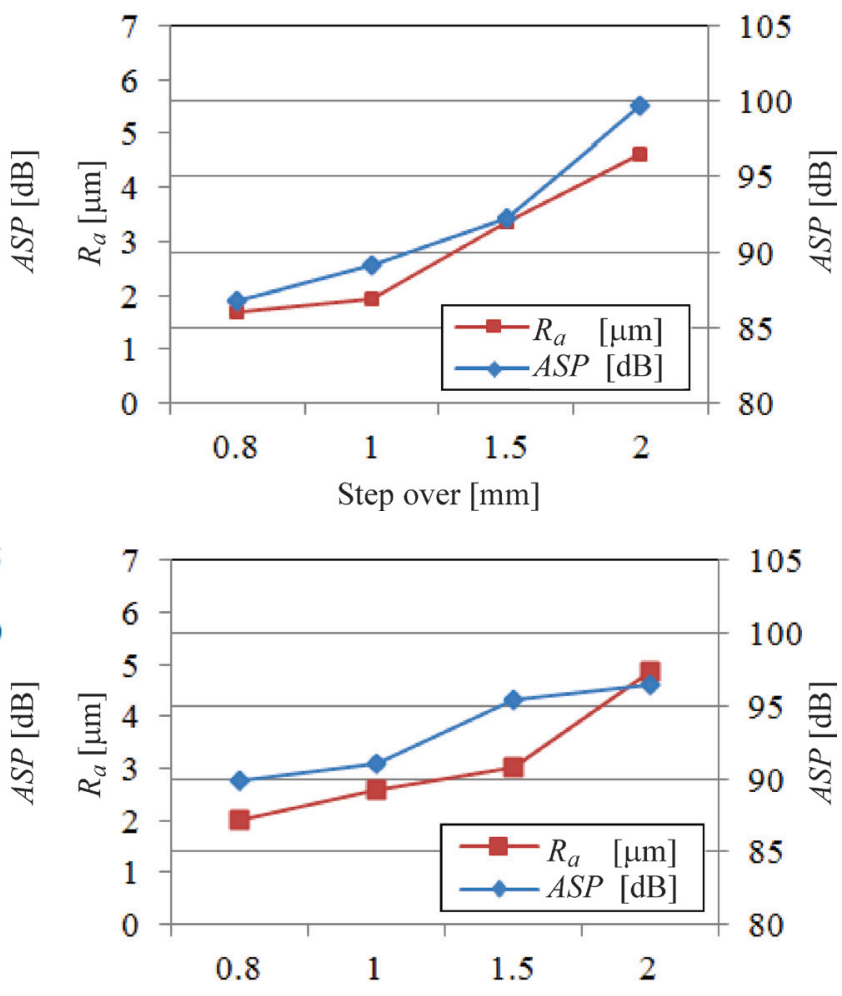

Step over $[\mathrm{mm}]$

95

90 \&
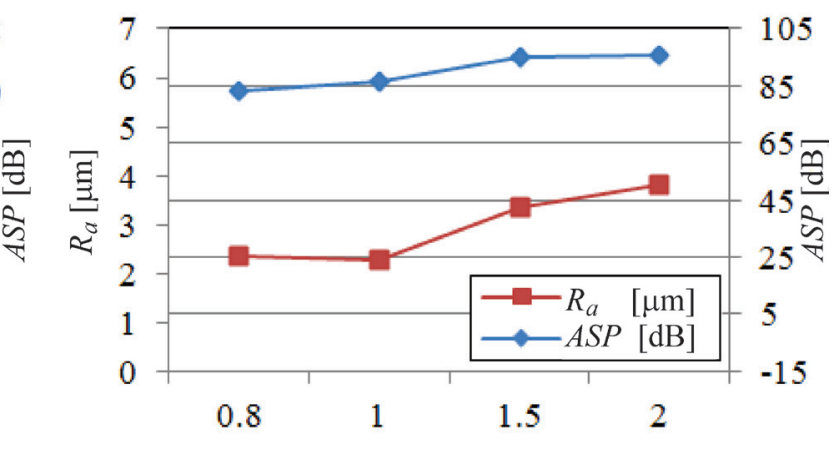

Step over [mm]

Fig. 6. $R_{a}$ versus ASP for; a) TiC, b) TiN, and c) TiAIN as to feed rate and step over levels in concave surface

$0.8 \mathrm{~mm}$. In Fig. 6b, for the TiN coating, the largest values of $R_{a}$ and $A S P$ have been observed at the feed rate of $414 \mathrm{~mm} / \mathrm{rev}$ and the step over of $2 \mathrm{~mm}$. The lowest values of $R_{a}$ and $A S P$ have been observed at the feed rate of $318 \mathrm{~mm} / \mathrm{rev}$ and the step over of 0.8 mm. Finally in Fig. $6 \mathrm{c}$, for the TiAlN coating, the largest values of $R_{a}$ and $A S P$ have been detected at the feed rate of $445 \mathrm{~mm} / \mathrm{rev}$ and the step over of $2 \mathrm{~mm}$. The lowest values of $R_{a}$ and $A S P$ have been observed at the feed rate of $350 \mathrm{~mm} / \mathrm{rev}$ and the step over of 0.8 $\mathrm{mm}$.
In this study, linear regression analysis was carried out to determine the relationship between the sound pressure level and surface roughness average. Linear regression is represented as [26]:

$$
S=\beta_{0}+\beta_{1} x_{1}+\ldots .+\beta_{i} x_{i}+\beta_{n} x_{n}+\varepsilon,
$$

where, $S$ represents the response and $\beta_{i}$ represents a regression factor of $i^{\text {th }}$ and residual. $\varepsilon$ is a random defect term and is presumed to show normal distribution having average zero with $\sigma_{2}$ variance.

The standardized residual is the residual divided by the standard deviation, where the residual is the 
Normal Probability Plot

TiC (response is $R_{a}$ )

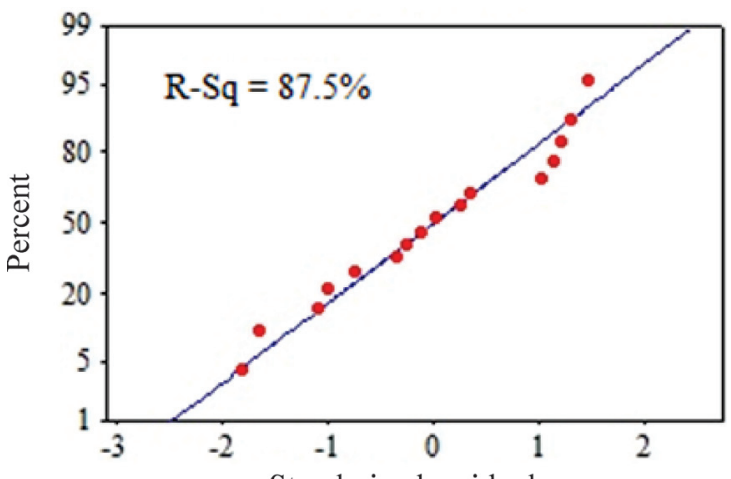

a)

Standarized residual

Normal Probability Plot

TiN (response is $R_{a}$ )

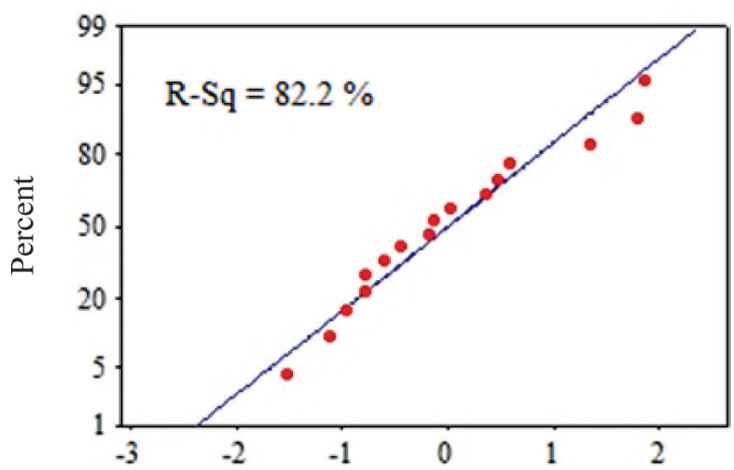

b)

Standarized residual

Normal Probability Plot

TiAIN (response is $R_{a}$ )

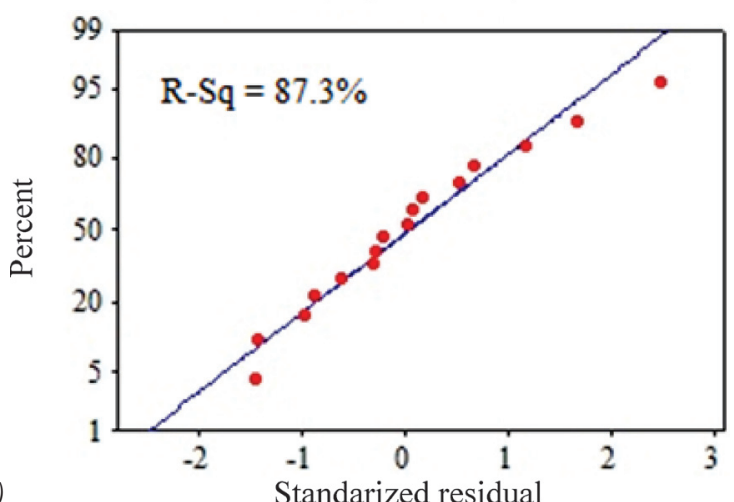

Fig. 7. ASP as a function of Ra for; a) TiC, b) TiN, and c) TiAIN coatings in concave surface

difference between the data response and the fitted response. In other words, it is residual standardized to have standard deviation 1 [26]. According to linear regression analysis, it was found that the relationship between sound pressure level and surface roughness is positive, linear and statistically significant
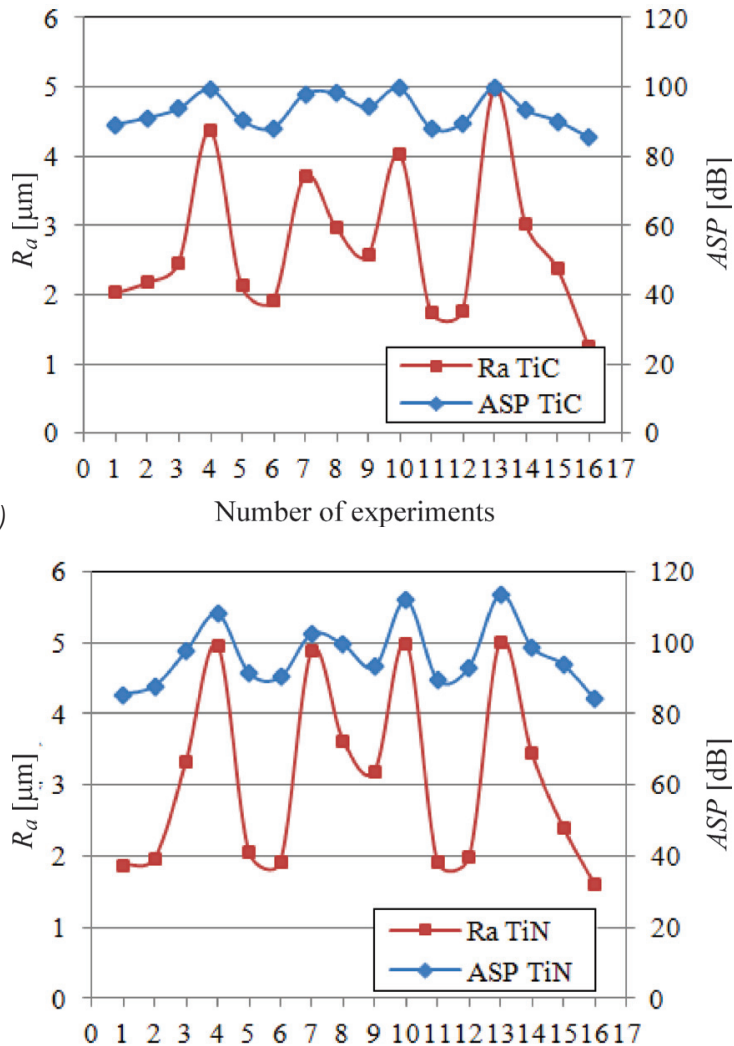

b)

Number of experiments

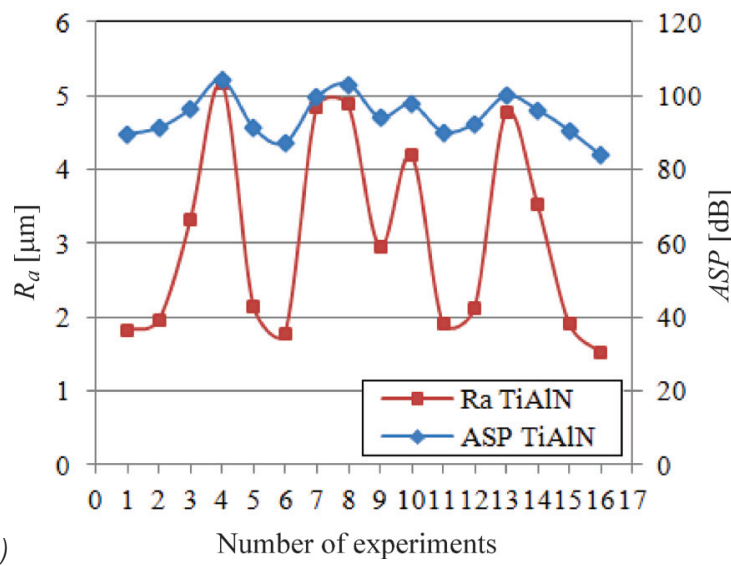

Fig. 8. $R_{a}$ versus ASP for; a) TiC, b) TiN, and c) TiAIN coatings in convex surface

(respectively $R^{2}=0.875 ; 0.822$ and 0.873 ) for TiC, TiN, and TiAIN (Fig. 7). When all cutting parameters are taken into consideration, it is determined that the correlation coefficient between sound pressure level and surface roughness is better than $R^{2}=0.8$. This shows that it is beneficial to adopt the sound pressure level during manufacturing.

Similarly, for convex surface forms, the ASP $[\mathrm{dB}]$ and surface roughness $[\mu \mathrm{m}]$ values which are 


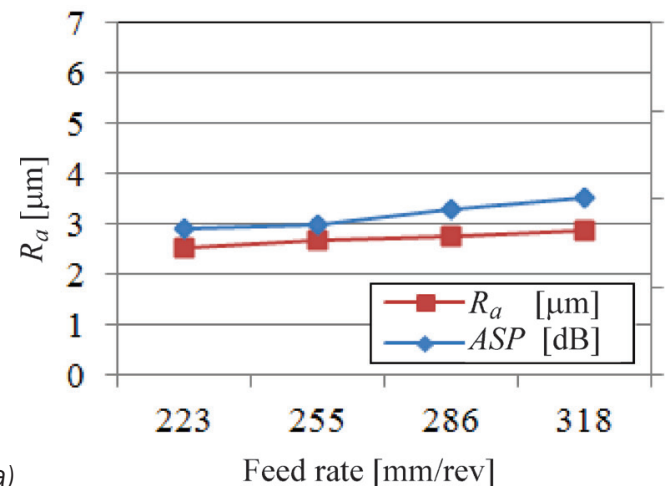

105

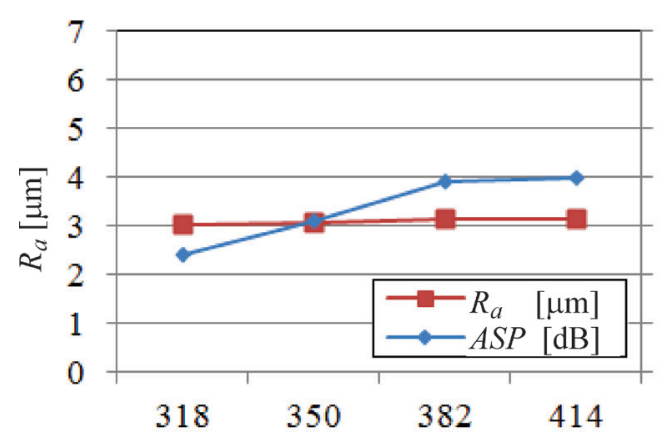

b)

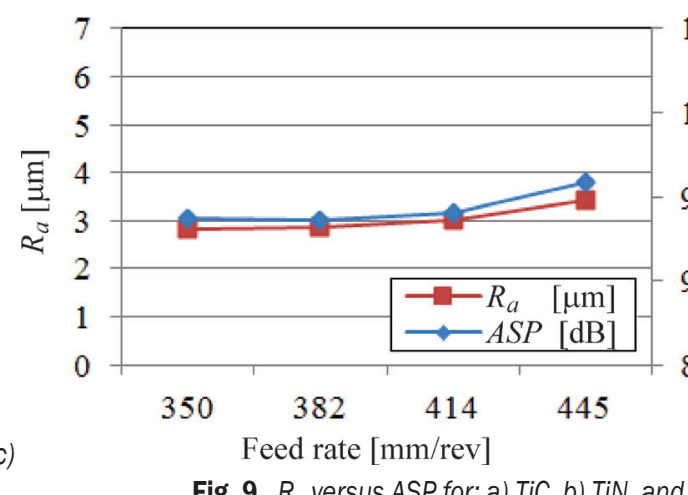

Fig. 9. $R_{a}$ versus ASP for; a) TiC, b) TiN, and c) TiAIN as to feed rate and step over levels in convex surface

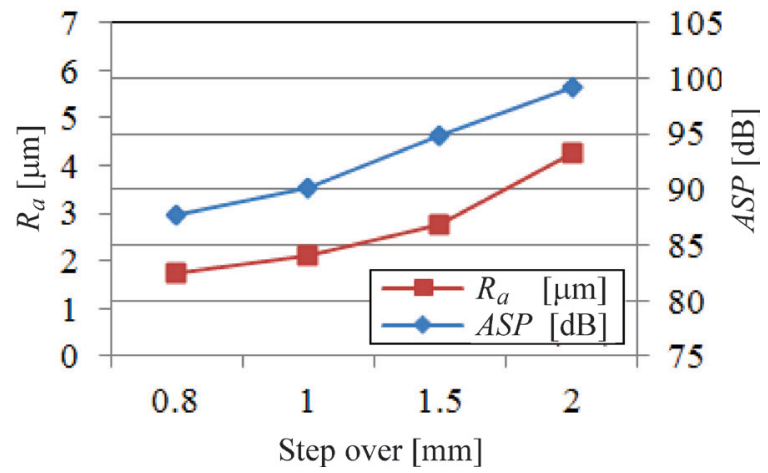

105

103

101

99

97

95

93

91

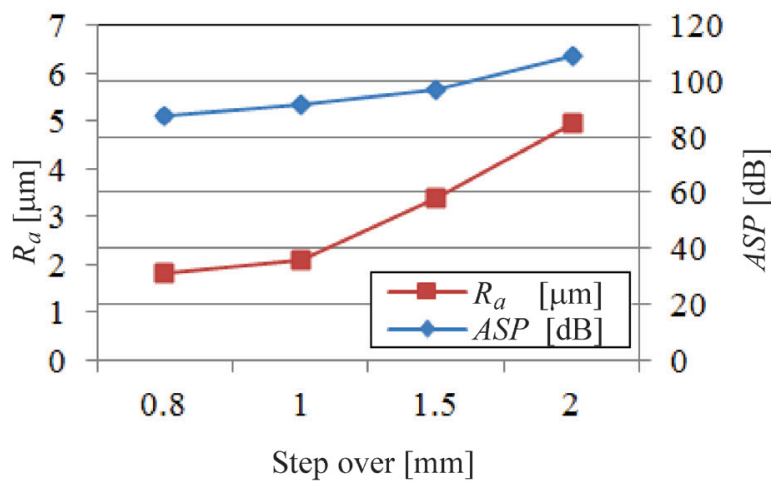

105

100

$95 \frac{\text { 吾 }}{\frac{5}{4}}$

90

85

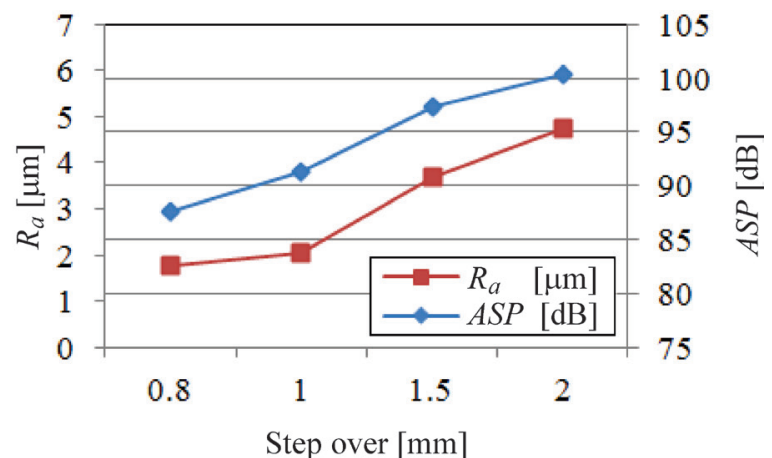

acquired from the experiments for the related coatings are shown in Fig. 8. When it is examined the acquired $A S P$ and $R_{a}$ graphics for TiC, TiN, and TiAIN coatings in Fig. 8, it is observed that surface roughness values increase with the increase of acoustic sound pressure as in concave surface type.

According to Fig. 8, for the cutter with $\mathrm{TiC}$ coating, the largest $A S P$ of $99.9 \mathrm{~dB}$ causes the largest $R_{a}$ value of $4.95 \mu \mathrm{m}$ at the experiment 13 . On the other hand, the lowest $A S P$ of $85.3 \mathrm{~dB}$ is observed at the $R_{a}$ value of $1.25 \mu \mathrm{m}$ at the experiment 16. For the cutter with TiN coating, the largest ASP of $113.4 \mathrm{~dB}$ resulted in the largest $R_{a}$ value of $5.01 \mu \mathrm{m}$ at the experiment 13. The lowest $A S P$ of $84 \mathrm{~dB}$ is observed at the $R_{a}$ value of $1.59 \mu \mathrm{m}$ at the experiment 16 . Lastly, for the cutter with TiAlN coating, the largest ASP of 104.1 $\mathrm{dB}$ resulted in the largest $R_{a}$ value of $5.16 \mu \mathrm{m}$ at the experiment 4. On the other hand, the lowest ASP of $83.7 \mathrm{~dB}$ is observed at the $R_{a}$ value of $1.51 \mu \mathrm{m}$ at the experiment 16 .

Upon the evaluation of parameters ( $V f$ and $f p$ ), $A S P$ and $R_{a}$ values show an increase with the increase of feed rate and step over as happened in concave surface type. The effects of feed rate and step over values on acquired $A S P$ and $R_{a}$ values are given in Fig. 9. As it is seen in Fig. 9a, for the TiC coating, the largest values of $R_{a}$ and $A S P$ have been observed at the feed rate of $318 \mathrm{~mm} / \mathrm{rev}$ and the step over of $2 \mathrm{~mm}$. The lowest values of $R_{a}$ and $A S P$ have been seen at the feed rate of $223 \mathrm{~mm} / \mathrm{rev}$ and the step over 
Normal Probability Plot

TiC (response is $R_{a}$ )

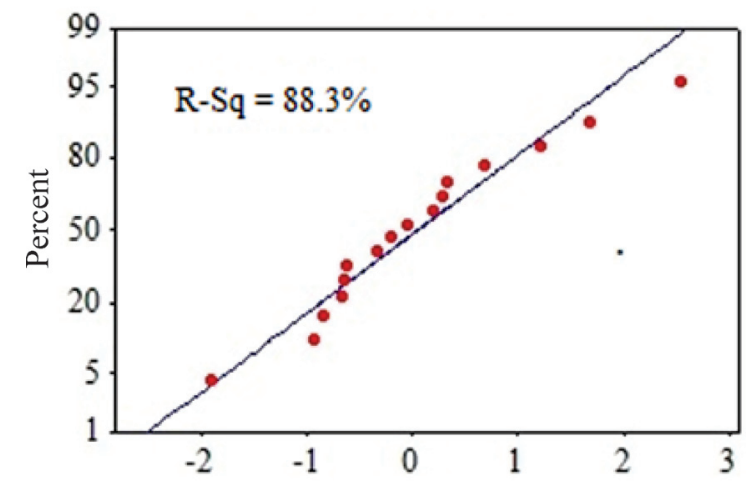

a)

Standarized residual

Normal Probability Plot

TiN (response is $R_{a}$ )

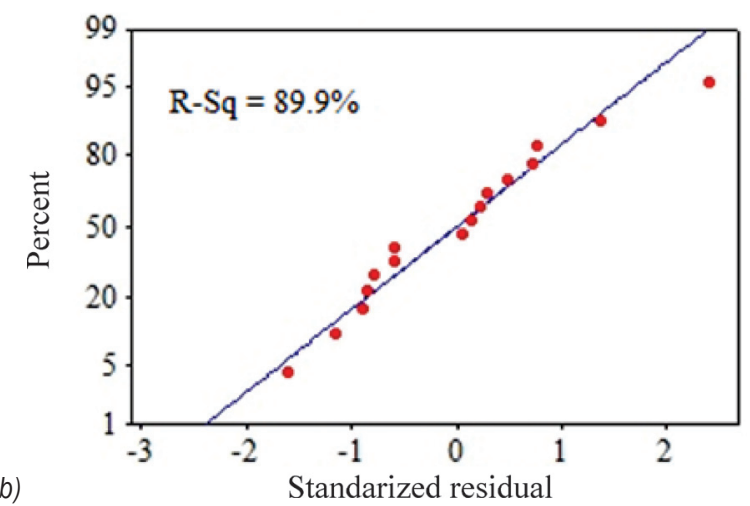

Normal Probability Plot

TiAIN (response is $R_{a}$ )

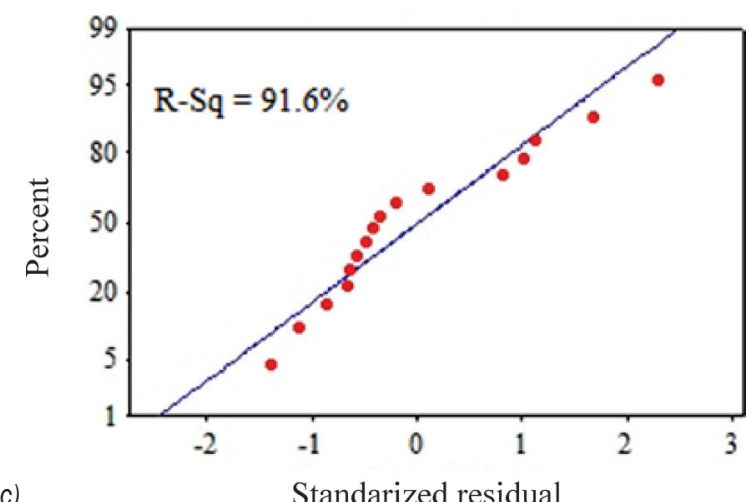

Fig. 10. ASP as a function of surface roughness for; a) TiC, b) TiN, and c) TiAIN coating in convex surface

of $0.8 \mathrm{~mm}$. On the other hand, in Fig. $9 \mathrm{~b}$, for the TiN coating, the largest values of $R_{a}$ and $A S P$ have been seen at the feed rate of $414 \mathrm{~mm} / \mathrm{rev}$ and the step over of $2 \mathrm{~mm}$. The lowest values of $R_{a}$ and $A S P$ have been observed at the feed rate of $318 \mathrm{~mm} / \mathrm{rev}$ and the step over of $0.8 \mathrm{~mm}$. Finally, in Fig. 9c, for the TiAlN coating, the largest values of $R_{a}$ and $A S P$ have been detected at the feed rate of $445 \mathrm{~mm} / \mathrm{rev}$ and the step over of $2 \mathrm{~mm}$. The lowest values of $R_{a}$ and $A S P$ have been observed at the feed rate of $350 \mathrm{~mm} / \mathrm{rev}$ and the step over of $0.8 \mathrm{~mm}$.

According to linear regression analysis, it has been found that the relationship between the sound pressure level for convex surface type and surface roughness is positive, linear and statistically significant (respectively $R^{2}=0.888 ; 0.899$ and 0.916 ) for TiC, TiN, and TiAIN (Fig. 10). Depending on all cutting parameters, it was determined that the correlation coefficient between surface roughness and sound pressure level is better than $R^{2}=0.8$. Again, this shows that it is beneficial to adopt the sound pressure level during manufacturing.

\section{CONCLUSION}

In this study, contouring and ramping cutting path styles set on down milling and up milling strategies were generated in concave and convex surfaces in semi finishing machining operations. In the experiments, the different tools with different coatings were employed. In addition, the relationship between surface roughness and cutting sound pressure level was observed with different levels of cutting velocity, feed rate and step over values. The indexable insert of ball end mills with $\mathrm{TiC}$, TiN, and TiAlN coatings were used for machining the formed inclined surfaces. As a result:

- The previous studies were focused on estimation of tool wear, vibrations stability and best cutting parameters by means of acoustic emission. In this study, the experiments on EN X40CrMoV5-1 material were carried out in order to understand the relationships between the sound signals generated and surface roughness in the machining of inclined concave and convex surfaces. The previous studies do not investigate the studied experimental cases of the inclined surfaces.

- The obtaining smaller ASP levels in concave surface shape machining (Fig. 5) in comparison to convex surface shape machining (Fig 8) might be explained by the surface form in which convex surface allows the microphone to gather the sounds with less obstruction.

- In convex surface shape machining when the all coatings are considered, the greater $A S P$ levels of 111.9 and $113.4 \mathrm{~dB}$ in the TiN coating have been seen at the experiments 10 and 13 as they are depicted in Fig. 8, respectively. The reason for that is that the ball end mill has less contact 
with the workpiece during the machining and it produces chatter mechanism. The surface roughness values belonging to those experiments are greater than of the other coatings as seen in Fig. 8.

- Acoustic sound pressure level decreased in the concave surface because the tool worked inside the workpiece and contacted the workpiece with the larger cutting edge in inner surface.

- After the evaluation of the sound pressure and surface roughness in terms of feed rate and step over parameters, the increase in the parameters raised $A S P$ and $R_{a}$ values without a dependency of tool coatings and surface shape.

- As for the effects of tool coatings on the values of $R_{a}$; in the experiments, TiAlN coating for low cutting velocity displayed a good performance, and the increase in feed rate and step over values raised $R_{a}$ values independent of tool coatings.

- The greater $A S P$ and $R_{a}$ values are formed for concave surface type in up milling strategy. The reason for that can be explained by chatter mechanism. The chatter occurred because of the type of surface, longer cutting tool and cutting tool's movement from less chip volume to more chip volume.

- $A S P$ and $R_{a}$ values of convex surface type in down milling strategy are higher than up milling. The overlap of cutting edges of the cutting tool on the workpiece increased both, sound pressure and surface roughness because up milling and the machined part were convex.

- It has been observed that in contouring, the $A S P$, which influences $R_{a}$, decreases with the increase in milling position angle.

- In ramping, the $A S P$, which again influences $R_{a}$, is hardly affected by the milling position angle.

\section{ACKNOWLEDGMENT}

The authors wish to thank Karabük University (Project code: KBÜ-BAP-C-11-D-004) for providing financial support to conduct this study.

\section{REFERENCES}

[1] Koksal, S. (2000). Face Milling of Nickel-Based Super Alloys with Coated and Uncoated Carbide Tools. $\mathrm{PhD}$ thesis, Coventry University, Coventry.

[2] Shaw, M.C. (2005). Metal Cutting Principles. Oxford University Press, Oxford.

[3] Wolter, B., Dobmann, G., Boller, C. (2011). NDT based process monitoring and control. Strojniški vestnik -
Journal of Mechanical Engineering, vol. 57, no 3, p. 218-226, DOI:10.5545/sv-jme.2010.172.

[4] Bagci, E., (2011). Monitoring and analysis of MRRbased feedrate optimization approach and effects of cutting conditions using acoustic sound pressure level in free-form surface milling. Scientific Research and Essays, vol. 6, no. 2, p. 256-277.

[5] Inasaki, I. (1998). Application of acoustic emission sensor for monitoring machining processes. Ultrasonics, vol. 36, p. 273-281, DOI:10.1016/S0041624X(97)00052-8.

[6] Jemielnaik, K., Otman, O. (1998). Tool failure detection based on analysis of acoustic emission signals. Journal of Materials Processing Technology, vol. 76, p. 192197, DOI:10.1016/S0924-0136(97)00379-8.

[7] Ghosh, N., Ravi, Y.B., Patra, A., Mukhopadhyay, S., Paul, S., Mohanty, A.R., Chattopadhyay, A.B. (2007). Estimation of tool wear during $\mathrm{CNC}$ milling using neural network-based sensor fusion. Mechanical Systems and Signal Processing, vol. 21, p. 466-479, DOI:10.1016/j.ymssp.2005.10.010.

[8] Marinescu, I., Axinte, D.A. (2008). A critical analysis of effectiveness of acoustic emission signals to detect tool and workpiece malfunctions in milling operations. International Journal of Machine Tools \& Manufacture, vol. 48, p. 1148-1160, DOI:10.1016/j. ijmachtools.2008.01.011.

[9] Marinescu, I., Axinte, D.A. (2009). A time-frequency acoustic emission-based monitoring technique to identify workpiece surface malfunctions in milling with multiple teeth cutting simultaneously. International Journal of Machine Tools \& Manufacture, vol. 49, p. 53-65, DOI:10.1016/j.ijmachtools.2008.08.002.

[10] Rivero, A., Lopez de Lacelle, L.N., Penalva, L.M. (2008). Tool wear detection in dry high-speed milling based upon the analysis of machine internal signals. Mechatronics, vol. 18, p. 627-633, DOI:10.1016/j. mechatronics.2008.06.008.

[11] Wilcox S.J., Reuben R.L., Souquet P. (1997). The use of cutting force and acoustic emission signals for the monitoring of tool insert geometry during rough face milling. International Journal of Machine Tools and Manufacture, vol. 37, p. 481-494, DOI:10.1016/S08906955(96)00069-7.

[12] Weingaertner, L.W., Schroeter, B.R., Polli, L.M., Gomes O.J., (2006). Evaluation of high-speed end-milling dynamic stability through audio signal measurements. Journal of Materials Processing Technology, vol. 179, p. 133-138, DOI:10.1016/j.jmatprotec.2006.03.075.

[13] Tekiner, Z., Yeşilyurt, S. (2004). Investigation of the cutting parameters depending on process sound during turning of AISI 304 austenitic stainless steel. Materials and Design, vol. 25, p. 507-513, DOI:10.1016/j. matdes.2003.12.011.

[14] Salgado, R.D., Alonso, J.F., (2007). An approach based on current and sound signals for in-process tool wear monitoring. International Journal of Machine Tools \& 
Manufacture, vol. 47, p. 2140-2152, DOI:10.1016/j. ijmachtools.2007.04.013.

[15] Ravindra, V.H., Srinivasa, G.Y., Krishnamurthy, R. (1997). Acoustic emission for tool condition monitoring in metal cutting. Wear, vol. 212, p. 78-84, DOI:10.1016/S0043-1648(97)00137-3.

[16] Haber, E.R., Jimenez, E.J., Peres, R.C., Alique, R.J. (2004). An investigation of tool-wear monitoring in a high-speed machining process. Sensors and Actuators, vol. 116, p. 539-545, DOI:10.1016/j.sna.2004.05.017.

[17] Quadro, L.A., Branco, J.R.T. (1997). Analysis of the acoustic emission during drilling test. Surface \& Coatings Technology, vol. 94-95, p. 691-695, DOI:10.1016/S0257-8972(97)00509-4.

[18] Guo, Y.B., Ammula, S.C. (2005). Real-time acoustic emission monitoring for surface damage in hard machining. International Journal of Machine Tools \& Manufacture, vol. 45, p. 1622-1627, DOI:10.1016/j. ijmachtools.2005.02.007.

[19] Asilturk, İ., Akkus, H., Demirci, T.M. (2011). Surface roughness modelling based on vibration, acoustic and cutting parameters via regression analysis. VI. Machine Design and Manufacturing Technologies Congress, p. 47-52.

[20] Horvat, J., Prezelj, J., Polajnar, I., Čudina, M. (2011). Monitoring gas metal arc welding process by using audible sound signal. Strojniški vestnik - Journal of
Mechanical Engineering, vol. 57, no 3, p. 267-278, DOI: $10.5545 /$ sv-jme.2010.181.

[21] Kek, T., Grum, J. (2009). AE signals as laser cutting quality indicators. Insight, vol. 51, no. 3, p. 124-128, DOI:10.1784/insi.2009.51.3.124.

[22] Chaari, R., Abdennadher, M., Louati, J., Haddar, M. (2011). Modelling of the 3D machining geometric defects accounting for workpiece vibratory behaviour. International Journal of Simulation Modelling, vol. 10, no. 2, p. 66-77, DOI:10.2507/IJSIMM10(2)2.173.

[23] Roy, S.S. (2010). Modelling of tool life, torque and thrust force in drilling: a neuro-fuzzy approach. International Journal of Simulation Modelling, vol. 9, no. 2, p. 74-85, DOI:10.2507/IJSIMM09(2)2.149.

[24] Gologlu, C., Sakarya, N. (2008). The effects of cutter path strategies on surface roughness of pocket milling of 1.2738 steel based on Taguchi method. Journal of Materials Processing Technology, vol. 206, p. 7-15, DOI:10.1016/j.jmatprotec.2007.11.300.

[25] Singh, S.K., Srinivasan, K., Chakraborty, D. (2004). Acoustic characterization and prediction of surface roughness. Journal of Materials Processing Technology, vol. 152 p. 127-130, DOI:10.1016/j. jmatprotec.2004.03.023.

[26] Montgomery, D.C., Peck, E.A., Vining G.G. (2006). Introduction to Linear Regression Analysis. Wiley, Hoboken. 